Conclusions: There was no marked difference in the US findings and the disease activity between the tendon sheath synovium and the joint synovium. However, there were differences in the local disease activities between the synovia. These results show that the tendon sheath synovium lacked acute inflammation. Disclosure of Interest: None declared DOI: 10.1136/annrheumdis-2018-eular.1707

\section{FRI0010 PREDICTION OF RADIOGRAPHIC PROGRESSION IN PATIENTS WITH RHEUMATOID ARTHRITIS BY BOTH MAGNETIC RESONANCE IMAGING AND ULTRASOUND}

A. Takatani ${ }^{1}$, M. Tamai ${ }^{1}$, N. Ohki ${ }^{2}$, Y. Nakashima ${ }^{1}$, Y. Endou ${ }^{1}$, S. Tsuji ${ }^{1}$, T. Shimizu ${ }^{1}$, M. Umeda $^{1}$, S. Fukui ${ }^{1}$, R. Sumiyoshi ${ }^{1}$, A. Nishino ${ }^{1}$, T. Koga ${ }^{1}$, S. Kawashiri ${ }^{1}$, N. Imamoto ${ }^{1}$, T. Igawa ${ }^{1}$, K. Ichinose ${ }^{1}$, K. Arima ${ }^{3}$, H. Nakamura ${ }^{1}$, T. Origuchi ${ }^{1}$, S. Sato ${ }^{4}$, M. Uetani ${ }^{2}$, A. Kawakami ${ }^{1}{ }^{1}$ Department of Immunology and Rheumatology; ${ }^{2}$ Department of Radiological Sciences; ${ }^{3}$ Department of Public Health, Nagasaki University Graduate School of Biomedical Sciences; ${ }^{4}$ Clinical Research Center, Nagasaki University Hospital, Nagasaki, Japan

Background: Magnetic resonance imaging (MRI) and ultrasound (US) are both useful modality to monitor disease status of RA whereas combination analysis of disease course by both modalities are quite few.

Objectives: To clarify the predictors of radiographic progression in patients with RA examined by both MRI and US.

Methods: Thirty-three patients with active RA, managed with a treat-to-target strategy and checked disease activity score every three months along with examination of both MRI and US, were enrolled from June 2010 to June 2016 and observed for 12 months. US of wrist and finger joints was examined every three months, MRI and radiograph were done every six months. US were evaluated by synovitis score of semi-quantitative manner by gray-scale (GS) and power Doppler (PD) proposed from EULAR. In MRI, synovitis, bone oedema and bone erosion were assessed by the Rheumatoid Arthritis Magnetic Resonance Imaging Scoring system (RAMRIS). Radiographic bone erosion and joint space narrowing (JSN) were scored by Genant-modified Sharp Score (GSS). Radiographic progression was defined as delta radiographic score $>0.5$. Multivariate analysis was employed to clarify independent predictors for radiographic progression at 12 month.

Results: Thirteen patients were treated with methotrexate monotherapy and eighteen were received combination of methotrexate and biologics. Three were given biologic monotherapy. Median of age was 57.0 years and that of disease duration was 9 months. Female was $84.8 \%$, positive rate of RF was $87.1 \%$ and that of ACPA was $79.3 \%$. DAS28-CRP was 4.20 , total GS score 6.0 , total PD score 4.0, MRI synovitis score 6.0, MRI bone oedema score 3.0, MRI bone erosion score 3.0, and GSS score 1.0 at baseline. Radiographic progression was found in 12 patients. Multivariate analysis revealed that high MRI bone oedema score at baseline, high MRI bone oedema score and $\mathrm{PD} \geq$ grade 2 articular synovitis at any joints at 6 month were associated with radiographic progression at 12 months. Clinical indices of DAS28-CRP at any point did not predict radiographic progression compared with MRI or US.

\begin{tabular}{|c|c|c|c|}
\hline & odds ratio & $95 \% \mathrm{Cl}$ & $\mathrm{p}$-value \\
\hline MRI bone edema score at Om & 1.52 & $1.06-2.17$ & 0.02 \\
\hline CRP at Om & 4.75 & $0.29-77.74$ & 0.28 \\
\hline GSS JSN at Om & 1.05 & $0.80-1.38$ & 0.72 \\
\hline
\end{tabular}

\begin{tabular}{|c|c|c|c|}
\hline MRI bone edema score at $6 \mathrm{~m}$ & 1.37 & $1.04-1.81$ & 0.03 \\
\hline CRP at $6 \mathrm{~m}$ & 7.00 & $0.96-51.15$ & 0.06 \\
\hline
\end{tabular}

\begin{tabular}{|c|c|c|c|}
\hline $\mathrm{PD} \geqq$ grade 2 at $6 \mathrm{~m}$ & 13.84 & $1.84-104.03$ & 0.01 \\
\hline $\mathrm{CRP}$ at $6 \mathrm{~m}$ & 8.24 & $0.59-115.45$ & 0.12 \\
\hline
\end{tabular}

Conclusions: During treat-to-target strategy, the presence of MRI bone oedema as well as $\mathrm{PD} \geq$ grade 2 articular synovitis are found to be important to predict radiographic outcome in active RA patients. These imaging indices may be more sensitive to monitor radiographic progression as compared with clinical indices.

Disclosure of Interest: None declared

DOI: 10.1136/annrheumdis-2018-eular.4555

\section{FRI0011}

ULTRASONOGRAPHIC CRITERIA FOR THE DIAGNOSIS OF EROSIVE RHEUMATOID ARTHRITIS DISEASE USING OSTEOARTHRITIC PATIENTS AS CONTROLS COMPARED TO VALIDATED RADIOGRAPHIC CRITERIA

C. Roux ${ }^{1}$, F. Gandjbakhch ${ }^{2}$, A. Pierreisnard ${ }^{2}$, M. Couderc ${ }^{3}$, C. Lukas ${ }^{4}$, R. Masri ${ }^{5}$, J.-P. Sommier ${ }^{1}$, I. Clerc-Urmes ${ }^{6}$, C. Baumann ${ }^{6}$, I. Chary-Valckenaere ${ }^{1}$, D. Loeuille

${ }^{1} .{ }^{1}$ Rheumatology, University Hospital of Nancy, Vandoeuvre-lès-Nancy;

${ }^{2}$ Rheumatology, Academic Hospital Pitie Salpêtrière, Paris; ${ }^{3}$ Rheumatology, University Hospital of Clermont- Ferrand, Clermont- Ferrand; ${ }^{4}$ Rheumatology, University Hospital of Lapeyronie, Montpellier, ${ }^{5}$ Rheumatology, University Hospital of Nancy, Vandoeuvre-lès-Nancy; ${ }^{6}$ Platform of Clinical Research Support PARC, University Hospital of Nancy, Vandoeuvre-lès-Nancy, France

Background: Rheumatoid arthritis $(\mathrm{RA})$ is the most prevalent chronic inflammatory joint disease ${ }^{1,2}$ responsible for structural damage. Radiography $(R X)$ is considered as the gold standard for visualising and quantifying bone lesions in RA. ${ }^{3}$ Musculoskeletal ultrasound (US) is booming in clinical practice for the diagnosis of RA. US can detect more erosions than RX at the joint level, especially at an early stage of the disease. ${ }^{4}$

Objectives: To determine thresholds for the diagnosis of erosive RA by US in RA and osteoarthritic $(\mathrm{OA})$ patients and to compare these US thresholds with $\mathrm{RX}$ ACR/EULAR 2013 criteria for erosive RA.

Methods: Patients fulfilling ACR 1987 and/or ACR/EULAR 2010 criteria for RA or hand OA criteria were prospectively included. A modified Sharp erosion score was assessed by two blinded readers and one adjudicator for discordant cases (number of eroded joints $\leq$ three). Erosions in US were scored on six bilateral joints (MCP2-3, 5; MTP2-3,5) with a four-grade scale to calculate total US score for erosions (USSe).

Results: A total of 168 patients were included: $122 \mathrm{RA}$ (32 early RA $<2$ years; 90 late $R A \geq 2$ years); 46 OA patients. On RX: 42 RA patients ( 6 early; 36 late) and 5 OA patients were eroded according to ACR/EULAR 2013 criteria with sensitivity at $34.4 \%$ and specificity at $89.1 \%$. On US, 95 RA patients (21 early; 78 late) and 12 OA patients were eroded. Considering at least two joint facets eroded or at least one joint facet eroded at grade 2 on US, sensitivities were good $(68 \%$ $72.1 \%)$ and specificities excellent $(89.1 \%-100 \%)$. Agreement between RX and US was excellent (90\%-92\%). US diagnosed two times more patients than RX as erosive disease in both early and late RA patients.

Conclusions: USSe can differentiate RA from OA in erosive disease and detect two times more patients with erosive RA than RX with excellent specificity and agreement, according to two different criteria (number of facets eroded and severity of erosion at the joint facet level).

\section{REFERENCES:}

[1] Guillemin F, et al. Prevalence of rheumatoid arthritis in France: 2001. Ann Rheum Dis 2005 Oct;64(10):1427-30.

[2] Alamanos $Y$, et al. Incidence and prevalence of rheumatoid arthritis, based on the 1987 American College of Rheumatology criteria: A systematic review. Semin Arthritis Rheum 2006 Dec;36(3):182-8.

[3] Baillet A, et al. Comparison of the efficacy of sonography, magnetic resonance imaging and conventional radiography for the detection of bone erosions in rheumatoid arthritis patients: a systematic review and metaanalysis. Rheumatol Oxf Engl 2011 Jun;50(6):1137-47.

[4] Wakefield RJ, et al. The value of sonography in the detection of bone erosions in patients with rheumatoid arthritis: a comparison with conventional radiography. Arthritis Rheum 2000 Dec;43(12):2762-70.

Disclosure of Interest: None declared

DOI: 10.1136/annrheumdis-2018-eular.2832

\section{FRI0012 SHARING THE BURDEN OF RHEUMATOID ARTHRITIS THROUGH REMOTE MONITORING OF RHEUMATOID ARTHRITIS (REMORA): IMPLICATIONS FOR PATIENTS AND CLINICIANS}

C.A. Sharp ${ }^{1}$, L. Austin ${ }^{2}$, M. Machin ${ }^{3}$, J. Humphreys ${ }^{4}$, P. Mellor ${ }^{4}$, J. McCarthy ${ }^{5}$, S. van der Veer ${ }^{1}$, L. Davies ${ }^{2}$, J. Ainsworth ${ }^{6}$, C. Sanders ${ }^{2}$, W. Dixon ${ }^{1} .{ }^{1}$ Arthritis Research UK Centre for Epidemiology; ${ }^{2}$ NIHR School for Primary Care Research; ${ }^{3}$ The Farr Institute of Health Informatics Research; ${ }^{4}$ NIHR CLAHRC GM; ${ }^{5}$ Alliance Manchester Business School; ${ }^{6}$ Centre for Health Informatics, The University of Manchester, Manchester, UK

Background: People living with rheumatoid arthritis (RA) experience continuous, daily symptoms that fluctuate over time. Clinical decisions made by healthcare 